\title{
CFR of COVID-19: a comparison among different countries
}

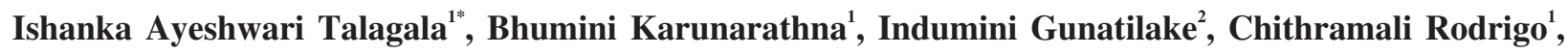
Dharshini Kantharuban ${ }^{3}$, Maheeka Seneviwickrama ${ }^{4}$, Pushpa Jayawardana ${ }^{5}$, Sampatha Goonewardena ${ }^{4}$
\end{abstract}

${ }^{1}$ Ministry of Health, Sri Lanka; ${ }^{2}$ Post Graduate Institute of Medicine, University of Colombo, Sri Lanka; ${ }^{3}$ Provincial Director of Health Services office, Eastern province, Trincomalee, Sri Lanka; ${ }^{4}$ Department of Community Medicine, Faculty of Medical Sciences, University of Sri Jayewardenepura, Sri Lanka; ${ }^{5}$ No affiliation

*Correspondence: drishankancd@gmail.com

iDhttps://orcid.org/0000-0001-6351-2079

DOI: https://doi.org/10.4038/jccpsl.v26i5.8352

Received on 18 May 2020

Accepted on 25 May 2020

\section{Highlights}

- Delay adjusted case fatality rate (CFR) would be a better epidemiological mortality measure to explain the severity of COVID-19 pandemic, compared to CFR and confirmed CFR.

- CRF of COVID-19 is lower compared to several known infectious diseases.

- CFR of COVID-19 increases with age and the presence of underlying chronic diseases.

CFR as an epidemiological measure in COVID-19

COVID-19 infection was first witnessed in China and has now spread across the globe creating a pandemic situation (1). As of 30 May 2020, there were $6,148,605$ confirmed cases and 370,473 deaths worldwide (2). In comparison, there were 1,630 confirmed cases with 10 deaths in Sri Lanka (3). In the epidemiological description of this pandemic, several morbidity and mortality measures were used to describe the disease burden. Accurate and reliable epidemiological measures are essential in outbreak/epidemic/pandemic situations as such measures give an insight into the spread of the disease, burden, risk factors, severity of the disease and its trends. In addition, these parameters would enable further planning of the control measures to mitigate its distribution, planned provision of limited healthcare resources to combat the epidemic/pandemic situation and allow within and cross-country comparisons. Among such epidemiologic measures, case fatality rate (CFR) has been a frequently used measure for estimating the severity and impact of the disease on the affected population.

Case fatality rate is defined as "the proportion of cases of a condition of interest who die of the condition within a specified period of follow-up after diagnosis and/or medical intervention, often expressed as percentages of deaths in a one-year or five-year period..." (4). Thus, the accuracy of CFR depends on its numerator, which is the number of 
deaths caused by the condition of interest, as well as the denominator, which is the total number infected with/suffering from the condition of interest. Several external factors such as the availability and capacity of healthcare workers, availability of other required healthcare resources, testing facilities, the capacity and ability to detect asymptomatic individuals and/or individuals with mild symptoms and the casedefinition that is being used could affect the number of total cases detected, which could directly affect the denominator (5). Also, if deaths due to another cause is being inadvertently counted or if a death due to the disease/condition of interest is not included (e.g. death of an asymptomatic), it could affect the numerator (6). Owing to these inaccuracies, as with any epidemiological measure, CFR has its own limitations, where it could be either under-estimated or over-estimated. Therefore, when it comes to international comparisons, it is best that CFR is used only for countries that use the same case-definition, similar procedures to detect the cases and deaths, and adopt similar efforts to detect the cases affected by the condition of interest (7).

When considering the CFR of countries using different case-definitions for international comparison, the best epidemiological measure would be to utilize 'confirmed CFR'. In confirmed CFR, the denominator would use only the laboratoryconfirmed cases instead of the total number of cases (7). Therefore, this measure will not be suitable to compare countries that use different testing methods (7). It is also important to note that the time-lag between infection/diagnosis and death could affect both the confirmed and conventional CFR. At the initial stages of an epidemic, case detection would be very high compared to the number of deaths, resulting in an under-estimation of the CFR. Also, as the number of deaths is caused by individuals who had been infected several days earlier, it is not correct to compare the deaths on a particular day with the cases detected on the same day (7).

Considering this limitation associated with CFR and confirmed CFR, 'delay-adjusted CFR' was developed by Russell et al. (2020) (unpublished), which took into consideration the time-lag between the point of diagnosis and death (8). This time-lag between diagnosis and death is considered to be between 7-14 days for COVID-19(9).

\section{CFR of COVID-19 pandemic}

It is understood that CFR may differ along the course of an epidemic (5). Considering the COVID-19 pandemic, a study done among 41 hospitalized, laboratory-confirmed patients during the initial period (2 January 2020) of the outbreak in Wuhan, China - the epicenter of this pandemic-, reported that the CFR was as high as $15 \%$, where six out of 41 confirmed cases had died (10). However, subsequently, a meta-analysis that included 50,466 COVID-19 patients in China revealed the CFR of COVID-19 infection to be $4.3 \%$. Later on, the Government of China announced that the CFR of COVID-19 was as low as $3.36 \%$ (11).

\section{CFR of COVID-19 compared to other} infectious diseases

It is known that the CFR of COVID-19 is much lower than that of Severe Acute Respiratory Syndrome (SARS) (15\%) and Middle East Respiratory Syndrome (MERS) (35\%) (12-13). The CFR of COVID-19 compared to other known infectious diseases is shown in Figure 1.

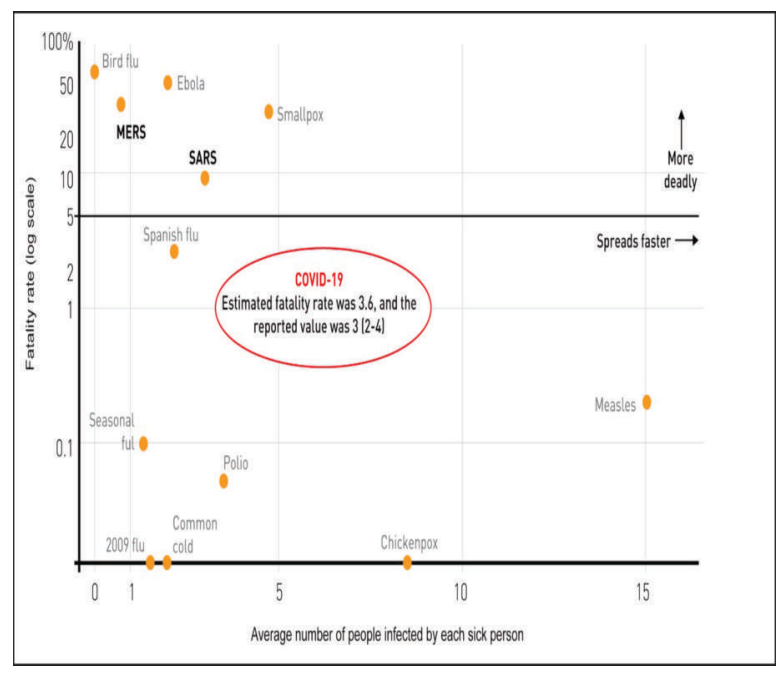

Figure 1. The CFR of COVID-19 compared to other known infectious diseases

Source: Khafaie MA and Rahim F, 2020 (14) 


\section{Comparison of CFR of COVID-19 across countries}

A study which compared the CFR among countries that reported a large number of COVID-19 cases (equal or more than 1000 cases) at two time points of the pandemic, namely 12 March 2020 and 23 March 2020 , reported that Italy $(6.22 \%)$, China $(3.91 \%)$, Iran $(3.62 \%)$, USA (3.07\%) and Spain (2.12\%) had the highest CFR on 12 March 2020 (14). Although the COVID-19 cases reported from China was the highest at both time points $(80,783$ on 12 March versus 81,093 on 23 March), the CFR was reported to be highest in Italy ( $6.2 \%$ on 12 March versus $9.26 \%$ on 23 March). However, by 23 March 2020, Italy (9.26\%), Iran (7.79\%), Spain $(6.16 \%)$, the United Kingdom (4.94\%) and the Netherlands (4.26\%) were the countries with the highest CFR (14). As of 30 May 2020, the CFR of Sri Lanka has been 0.61\% (1630 confirmed COVID-19 cases and 10 deaths) (3) compared to much higher CFRs reported from other countries (Figure 2).

\section{Comparison of CFR of COVID-19 across age categories}

It is essential to know which age groups are affected most by the infection in an epidemic/pandemic, so that effective preventive measures can be undertaken for the high-risk groups. It is shown that the CFR of COVID-19 increases with age $(7,16)$ across different countries (Table 1).

Table 1. Confirmed CFRs of COVID-19 for different countries, at different age groups

\begin{tabular}{|lcccccc|}
\hline \multirow{2}{*}{ Age group (years) } & \multicolumn{7}{c|}{ Confirmed CFR } \\
\cline { 2 - 7 } & China* & Germany** & Italy** & South Korea** & Spain** & Sweden** \\
\hline $0-9$ & 0.0 & 0.0 & 0.1 & 0.0 & 0.2 & 0.0 \\
$10-19$ & 0.2 & 0.0 & 0.0 & 0.0 & 0.3 & 0.0 \\
$20-29$ & 0.2 & 0.0 & 0.1 & 0.0 & 0.3 & 0.4 \\
$30-39$ & 0.2 & 0.0 & 0.3 & 0.1 & 0.3 & 0.3 \\
$40-49$ & 0.4 & 0.2 & 0.9 & 0.2 & 0.6 & 0.7 \\
$50-59$ & 1.3 & 0.4 & 2.5 & 0.7 & 1.3 & 2.0 \\
$60-69$ & 3.6 & 2.1 & 9.5 & 2.5 & 4.5 & 6.0 \\
$70-79$ & 8.0 & 9.4 & 24.1 & 9.7 & 14.1 & 18.3 \\
$>80$ & 14.8 & 30.6 & 28.8 & 22.9 & 23.9 & 28.2 \\
\hline Total & $\mathbf{2 . 3}$ & $\mathbf{2 . 7}$ & $\mathbf{1 2 . 6}$ & $\mathbf{2 . 2}$ & $\mathbf{8 . 1}$ & $\mathbf{1 0 . 6}$ \\
\hline
\end{tabular}

*Source-China CDC Weekly- as of February 11, 2020 (16)

**Source-Gianicolo et al., 2020 - as of April 16,2020 (7)

It is shown that in 2020, 23.1\% of the Italian population was either 65 years of age or older (17). This would explain the higher mortality rates of Italy compared to other countries.

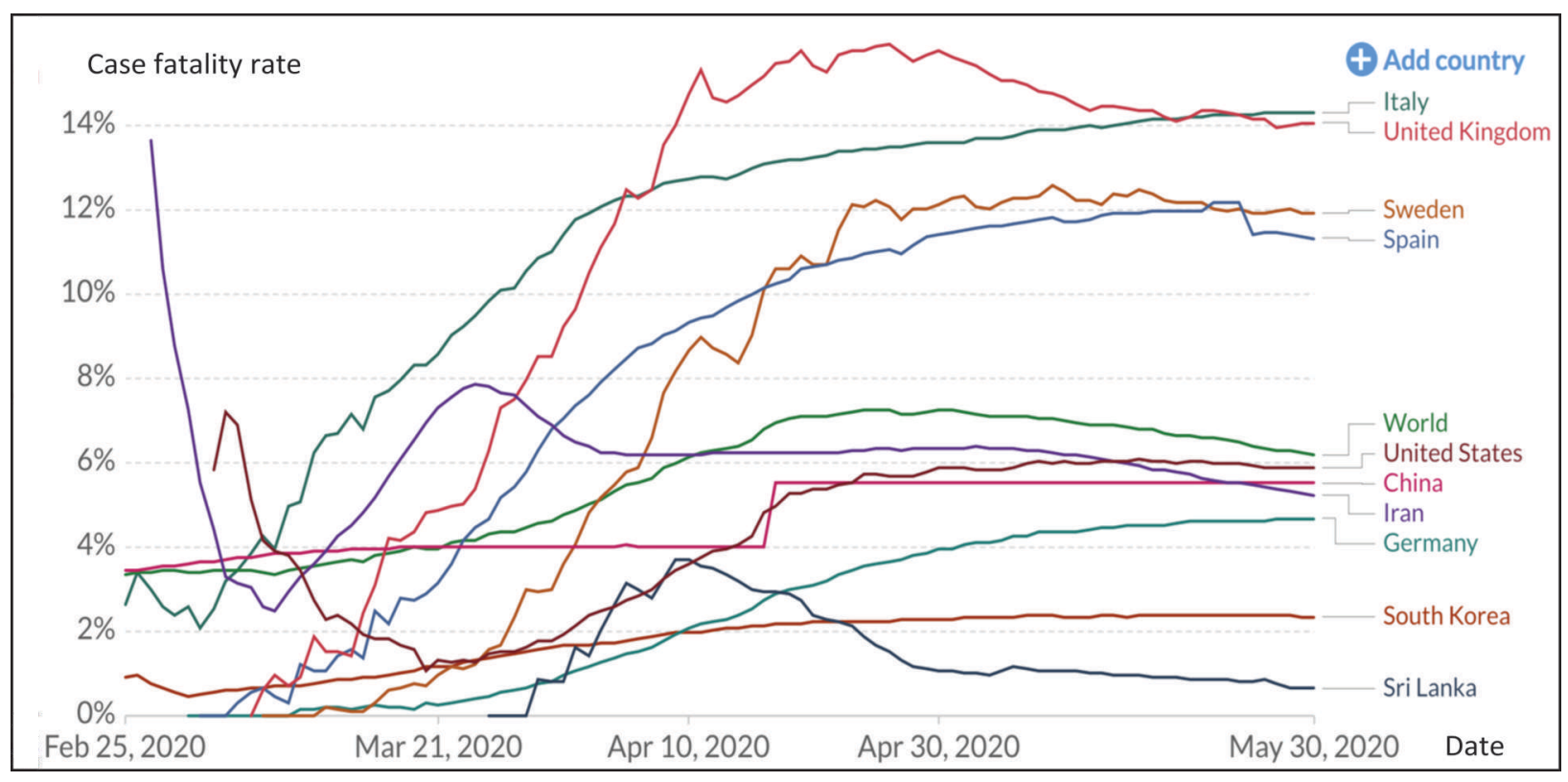

Figure 2. Comparison of CFRs of COVID-19 for several countries by 31 May 2020

Source: University of Oxford \& Oxford Martin School (15) 


\section{Comparison of CFR of COVID-19 with underlying comorbidities}

CFR for COVID-19 is shown to be increased with the presence of comorbidities $(16,18-19)$ such as hypertension $(\mathrm{CFR}=6.0 \%)$, diabetes $(\mathrm{CFR}=7.3 \%)$, cardiovascular disease $(\mathrm{CFR}=10.5 \%)$, chronic respiratory disease $(\mathrm{CFR}=6.3 \%)$ and cancer $(\mathrm{CFR}=5.6 \%)(16)$.

\section{Gaps in the knowledge}

While commending Sri Lanka for the tremendous activities and efforts that have been undertaken to limit the spread of the coronavirus disease and thereby its associated morbidities and mortality, it is important to note that local knowledge on several important statistics such as the CFR in relation to the age categories, underlying comorbidities and the time-lag between the point of diagnosis and death is lacking.

\section{Applicability of the evidence on CFR of COVID-19 to Sri Lanka}

In the absence of detailed information on the CFR of COVID-19 in Sri Lanka, the ongoing response process for COVID-19 is largely dependent on the findings from other countries. Considering the major role the time-lag from the point of diagnosis to the point of death plays in CFR, it is essential to have an insight on this, so that effective COVID-19 response planning could be undertaken. In addition, it is important to know the mortality rates related to the age categories and underlying comorbidities, so that stringent preventive plans could be implemented for high-risk populations and utilize the limited health resources effectively.

\section{Recommendations for the COVID-19 response in Sri Lanka}

Timely and accurate reporting of the deaths as well as confirmed cases is essential and therefore recommended. Although local data are not available, it is evident from other countries that the CFR of COVID-19 increases with the age and the presence of underlying comorbidities. Thus, stringent measures should be undertaken to prevent the spread of infection especially to the aged, and individuals with chronic diseases. In addition, limited healthcare resources should be planned and utilized effectively being vigilant on these high-risk groups.

\section{Author Declaration}

Author contributions: IT and BK have made substantial contributions to the conception, drafting and critical analysis for the intellectual content of the manuscript. All authors agreed to be accountable for all aspects of the work in ensuring that questions related to the accuracy or integrity of any part of the work are appropriately investigated and resolved. All authors have read and approved the manuscript.

\section{References}

1. World Health Organization. (2020). $Q \& A$ on coronaviruses (COVID-19). Available from:https://www.who.int/emergencies/diseases/ novel-coronavirus-2019/question-and-answershub/q-a-detail/q-a-coronavirus es. Accessed 30 May 2020.

2. Worldometer. Covid-19 Coronavirus Pandemic. Available from: https://www. worldometers. info/coronavirus/.20Accessed May 30, 2020.

3. Epidemiology Unit, Sri Lanka. Coronavirus disease 2019 (COVID-19). Situation Report, 2 May 2020, 10.00am. Available from: http://www.epid.gov.lk/web/images/pdf/corona_ virus_report/sitrep-sl-en-02-05_10.pdf.

4. Porta, M., John M.L. (2018). A Dictionary of Public Health (2 ed.): Case fatality rate. Oxford University press. Available from https://www. oxfordreference.com/view/10.1093/acref/978019 1844386.001.0001/acref-9780191844386-e615 ? rskey $=\mathrm{s} 9 \mathrm{wGmF} \&$ result $=668$ Accessed 30 May 2020.

5. Rajgor DD, Lee MH, Archuleta S, Bagdasarian N, Quek SC. The many estimates of the COVID-19 case fatality rate. The Lancet Infectious Diseases 2020; 20(7): 776- 777. DOI: 10.1016/ S14733099(20)30244-9

6. Baud D, Qi X, Nielsen-Saines K, Musso D, Pomar L, Favre G. Real estimates of mortality following COVID-19 infection. The Lancet infectious 
diseases 2020; 20(7): 773. DOI: 10.1016/ S14733099(20)30195-X

7. Gianicolo E., Riccetti, N., Blettner, M., Karch, A. Epidemiological measures in the context of the COVID-19 pandemic. Deutsches Arzteblatt International 2020; 117(19): 336- 342. DOI:10.3238/arztebl .2020.0336.

8. Russell TW, Hellewell J, Abbott S, Jarvis CI, van Zandvoort K, CMMID nCov working group, Flasche S, Kucharski AJ. Using a delay-adjusted case fatality ratio to estimate under-reporting. Centre for Mathematical Modelling of Infectious Diseases Repository, London School of Hygiene, and Tropical Medicine. 2020. Available from: https:// fondazionecerm .it/wp-content/ uploads/ 2020/03/Using-a-delay-adjusted-case-fatalityratio-to-estimate-under-reporting-_-CMMIDRepository.pdf. Accessed 20 May 2020.

9. Wilson N., Kvalsvig A., Barnard T., Baker MG. Case-fatality risk estimates for COVID-19 calculated by using a lag time for fatality. Emerging Infectious Diseases 2020; 26(6): 13391441. DOI:10.3201/eid2606.200320.

10. Huang C, Wang Y, Li X, Ren L, Zhao J, Hu Y, Zhang L, Fan G, Xu J, Gu X, Cheng Z. Clinical features of patients infected with 2019 novel coronavirus in Wuhan, China. The Lancet 2020; 395(10223): 497-506. DOI: 10.1016/ S01406736(20)30183-5.

11. Sun P, Qie S, Liu Z, Ren J, Xi J. Clinical characteristics of 5732 patients with 2019-nCoV infection. Available from: http:// dx.doi.org/ 10.2139/ssrn.3539664. Accessed on 16 Feb 2020.

12. World Health Organization. Emergency Preparedness, response: Update 49 - SARS case fatality ratio, incubation period. 7 May 2003. Available from: https://www.who. int/ csr/sars/archive/2003_05_07a/en/. Accessed 30 May 2020.
13. World Health Organization. Middle East respiratory syndrome coronavirus (MERS-CoV). March 11, 2019. Available from:https:// www.who.int/news-room/fact-sheets/ detail/ middle-east-respiratory-syndrome-corona virus(mers-cov). Accessed 30 May 2020.

14. Khafaie MA, Rahim F. Cross-country comparison of case fatality rates of COVID-19/SARS-COV-2. Osong Public Health and Research Perspectives 2020; 11(2): 74. DOI: 10.24171/j.phrp. 2020.11.2.03.

15. University of Oxford \& Oxford Martin School. Our World in Data: Case fatality rate of the ongoing Covid-19 pandemic. Available from: https://ourworldindata.org/mortality-risk-covid . Accessed 30 May 2020.

16. The novel coronavirus pneumonia emergency response epidemiology team. The epidemiological characteristics of an outbreak of 2019 novel coronavirus diseases (COVID-19) - China, 2020. China CDC Weekly. 2020; 2(8): 113-122. DOI: 10.46234/ccdcw2020.032.

17. Statista Research Department. Percentage of elderly population in Italy from 2009 to 2020. Available from: https://www .statista. com/ statistics/785104/elderly-population-in-italy/. Accessed 30 May 2020.

18. Franki R. Comorbidities the rule in NewYork's COVID-19 deaths. The Hospitalist, April 8, 2020. Available from: https:/www.the-hospitalist.org/ hospitalist /article/220457/ coronavirus-updates/ comorbidities-rule-new-yorks-covid-19-deaths. . Accessed 30 May 2020.

19. Onder G, Rezza G, Brusaferro S. Case-fatality rate and characteristics of patients dying in relation to COVID-19 in Italy. JAMA. 2020; 323(18): 17751776. DOI: $10.1001 /$ jama .2020 .4683 . 